\title{
WHY FIGHTING STRUCTURAL INEQUALITIES REQUIRES INSTITUTIONALIZING DIFFERENCE: A RESPONSE TO NIENKE GROSSMAN
}

\author{
Neus Torbisco-Casals*
}

People ask me sometimes, when-when do you think it will be enough? When will there be enough women on the court? And my answer is when there are nine.

Justice Ruth Bader Ginsburg, U.S. Supreme Court ${ }^{1}$

\section{Introduction}

Nienke Grossman offers a much needed overview of the statistical patterns behind the substantial underrepresentation of women in international courts benches. As her inquiry reveals, despite the growing proportion of female qualified lawyers, sex representativeness has hardly improved in recent years. On the contrary, in the absence of special requirements in courts' statutes or judicial selection procedures, the percentage of women judges has actually stagnated or even declined in some cases. Such acute sex imbalance cannot be attributed to the (contingent) fact that not enough qualified women are available for such highly prestigious positions. Grossman persuasively contests the plausibility of this widespread assumption. Not only is the limited-pool argument fallacious, but, as her analysis suggests, part of the problem might actually be that judicial selection procedures lack transparency and are not driven by merit. Instead, nominations of international judges are often used "to reward political loyalty or to advance political agendas"; ${ }^{2}$ this practice seriously impinges on the chances of women to be appointed as international judges, as politics (both domestic and international) remains very much a male-dominated sphere.

Grossman call for reforms to tackle this long-standing deficit connects with a growing public awareness of the need to further the inclusion of women in political and legal institutions. Grossman herself cites recent campaigns - such as the International Geneva Gender Champions, and the Gqual Campaign for Gender Parity in International Representation ${ }^{3}$ - as a sign of the increasing political will to make the necessary reforms. Yet, in my opinion, moving beyond symbolic political commitments to foster legal reforms towards gender parity requires making the normative case more clear. Put differently: Unless there is a clear understanding that pervasive lack of sex representativeness in international institutions (and, particularly, in international courts) is not merely dysfunctional but also represents an injustice, those public initiatives may fail to instigate real change. Thus, in what follows, I shall mostly focus on the normative underpinnings that

\footnotetext{
* Visiting Professor, Graduate Institute of International and Development Studies (Geneva) \& Associate Professor, Universitat Pompeu Fabra (Barcelona).

Originally published online 09 September 2016.

${ }^{1}$ When will there be enough women on the Supreme Court? Justice Ginsburg answers that question, PBS NEwSHOUR (Feb. 5, 2015, 6:10 PM).

${ }^{2}$ Nienke Grossman, Achieving Sex-Representative International Court Benches, 110 AJIL 86 (2016).

${ }^{3}$ GQUAL; INTERNATIONAL GENEVA GENDER CHAMPIONS.
} 
might substantiate this claim. My goal is not to challenge Grossman's account, but to supplement it with several points aimed at strengthening the case for greater judicial diversity. I divide my observations in two parts. I begin by discussing the limited force of the legality argument put forward by Grossman in light of the pervasiveness of women's subordinated position in public life and then turn to sketching four normative arguments for gender parity on the bench.

\section{Reforming Sex-Unrepresentative Benches: Legality Constraints}

While the debate over the composition of the international judiciary is relatively new, the issue of women's underinclusion in public institutions has long been in the spotlight. To be sure, this phenomenon is part of a global trend: Women, just as other historically subordinated groups, are far less likely than men to occupy prestigious positions or top jobs virtually everywhere, and the explosive growth of female employment and access to higher education over the last decades has been insufficient to promote real sex equality. Grossman's discussion on how to achieve more gender-balanced international court benches is thus recognizably part of the broader discussion over what should be done to subvert the "glass ceiling" effect, which significantly impairs women's progress. ${ }^{4}$

From the legal perspective that concerns us here, it is crucial to note that women's subordinated position in the public realm has long persisted despite the widespread recognition of women's individual rights, and the long standing formal prohibition of sex-discrimination. In fact, Grossman's article vividly stresses the contemporary relevance of Hilary Charlesworth, Christine Chinkin, and Shelley Wright's powerful critique, more than twenty years ago, that the structures of international law privilege men. ${ }^{5}$ Grossman, nonetheless, claims that states are "legally required to take steps to understand and remedy the paucity of women judges on most international court benches." 6 To support this claim, she appeals to international human rights instruments which endorse sex equality and recognize, among other things, the right of women to be eligible under conditions of equality in international institutions.

However, in my view, the legality-based argument has limited force. ${ }^{7}$ This is basically because it overlooks the dominant interpretive frameworks of equality and nondiscrimination, which significantly undermine the kind of group-conscious approach that would justify the strong legal obligation that Grossman tries to press. Thus, prevailing understandings retain an individualist outlook, stressing equality of opportunity rather than equality of outcome, and this makes it difficult to tackle indirect forms of discrimination, or to take into account the disparate impact of social and political norms and practices on particular identity groups. Hence, antidiscrimination statutes typically aim at ensuring that no overt legal impediment can prevent anyone from pursuing their political and professional ambitions, or from participating in public life. Likewise, differenceblindness remains a deeply embedded ideal, despite criticisms that it obscures systemic patterns of discrimination. As a result, sex imbalances become "normalized," as they tend to be depicted as the product of individual choices.

The pervasiveness of this liberal model of rights explains why most states are not genuinely engaged in reforming sex-unrepresentative international institutions, as the present situation is not perceived as unlawful.

\footnotetext{
${ }^{4}$ For a comprehensive review see, especially, Chapters 4 (work) and 5 (power and decision-making) of the more recent UN World's Women Report. United Nations Statistics Division, The World's Women 2015: Trends and Statistics.

${ }^{5}$ Hilary Charlesworth et al., Feminist Approaches to International Law, 85 AJIL 613 (1991).

${ }^{6}$ Grossman, supra note 2, at 87.

${ }^{7}$ Cecily Rose's comment in this symposium also stresses this point, especially with regards to the limitations of article 8 of the UN Charter. See Cecily Rose, Justifying Arguments About Selection Procedures for Judges at International Courts and Tribunals: A Response to Nienke Grossman, 110 AJIL UnBOUND 86 (2016).
} 
Fostering the reforms advocated by Grossman might thus critically depend on transforming those interpretive patterns, and making room for an alternative difference-conscious approach that acknowledges that, when sex inequality is the norm, there are reasons to think that systemic forms of disadvantage prevent women from fully exercising their rights. Anne Marie Slaughter's controversial article in The Atlantic, "Why Women Still Can't Have It All," represents a powerful statement in this regard. ${ }^{8}$ Her honest account of her experience as a top officer at the U.S State Department is, I suspect, shared by many women who face the same uncomfortable realization that society and the economy are not organized so that women can "have it all." Men, instead, rarely experience the same type of constraints or hard choices. The late Iris M. Young reflected on the power of systemic inequalities in an interview I had the honor to conduct more than a decade ago. ${ }^{9}$ Asked whether she thought the challenges that younger generations of women face were different than the ones she encountered in the 1960s and 1970s as a young scholar in the United States, Young observed that, even if overt views about women's lesser competence might have declined "some of the most basic aspects of gender distinction and oppression remain"; more crucially, she stressed, "there remains a very strong gender division of labor in all societies that continues to expect that care work will be performed primarily by women, much or all of it unpaid in the home, and that housework will be done primarily by women. These expectations and assumptions continue to make life easier for a lot of men than a lot of women who also wish or need to work outside the home."10

The notion of structural inequality thus stands for something other than transitory, fortuitous disadvantages that may be the product of pure bad luck, or simply attributable to individual poor choices. As Young puts it, it primarily involves taking into account a "social structure," and "a set of reproduced social processes that reinforce one another to enable or constrain individual actions in many ways." 11 As a result, some people experience more constraints in their freedom and well-being, as compared with others who have more options and access to benefits. ${ }^{12}$ Structural inequalities therefore tend to be institutionally embedded, deeply rooted in rules, cultural symbols, and decision-making processes, so that individual agents acting within this framework (including members of oppressed groups) reinforce and perpetuate existing patterns of disadvantage, often unintentionally. Thereby, different group statuses are created and reproduced, triggering harmful effects which, as Owen Fiss argued in his influential piece "Groups and the Equal Protection Clause," are unlikely to be legally actionable as long as the ideal of equality is interpreted as merely embodying an antidiscrimination principle. ${ }^{13}$

In short, despite the proclaimed liberal democratic aspiration to impartiality, equality, and universal inclusion, mainstream institutions have historically privileged, explicitly or implicitly, the attributes of white, heterosexual, fully-abled, and patriotic males educated in the language and culture considered as prestigious. Women (as well as black, indigenous, or gay) identities were largely excluded from the public sphere and relegated to a lower status. Today, the illusion of autonomy projected by liberal legal culture obviates the persisting effects of those exclusions in hindering the opportunities of members in marginalized identity groups, whose preferences have often assimilated existing sociocultural prejudices. ${ }^{14}$ The limits of the domi-

\footnotetext{
8 Anne-Marie Slaughter, $\underline{W}$ by Women Still Can't Have It All, THE ATLANTIC, (July/Aug. 2012).

${ }^{9}$ Neus Torbisco-Casals \& Idil Boran, Interview with Iris Marion Young, 23 HypaTia 173 (2008).

$10 \underline{I d}$. at 175.

11 Iris M. Young, Equality of Whom? Social Groups and Judgments of Injustice, 9 J. POL. PHIL. 15 (2001).

${ }^{12} \underline{I d}$.

13 Owen M. Fiss, Groups and the Equal Protection Clause, 5 PHIL. \& PuB. AfF. 107 (1976).

14 See Kenji Yoshino, Covering, 111 YaLE L.J. 769 (2002).
} 
nant individual model of equality described so far are equally relevant, I think, for human rights standards under international law.

\section{The Case for Sex Parity in International Courts}

The previous considerations can help when responding to the key question of what is wrong with the scarcity of women in the international judiciary, and why Grossman is right in contending that steps need to be taken to reverse this situation. Let me now turn to outlining four normative reasons that could provide the grounds for reforms.

\section{Real sex equality}

For the reasons discussed so far, sex-unrepresentative benches confirm the unfair privileged position that men have been able to retain in the public sphere, despite the formal recognition of sex equality and women's rights. A number of social and institutional features and processes reinforce the unequal status of women, even in the absence of conscious discriminatory actions. This is so because gender remains deeply embedded in roles, behavioral patterns, and positions which have historically been structured in biased ways. This produces unequal effects for women, which, as I have just argued, cannot be reversed through prevailing individualist interpretive legal standards. Tackling structural inequalities thus requires a group-conscious interpretation of nondiscrimination as well as comprehensive social and institutional reforms ${ }^{15}$. In the case of the international judiciary, the logic of such reforms should not be just one of compensation or redistribution, but also of recognition. ${ }^{16}$ Hence, the aim should be to achieve gender parity, rather than just symbolic representation, as only equality of outcome validates equality of opportunity in circumstances of systemic disadvantage. ${ }^{17}$. As Anne Phillips writes:

If nothing were stopping people, if nothing got in their way, we would expect a roughly random distribution of political office and influence among all citizens: no marked preponderance of people with blue eyes, no marked preponderance of those with short hair. The only legitimate discrepancies would be those mapped on political salient characteristics. ${ }^{18}$

\section{Strengthening democratic legitimacy}

The consistent overrepresentation of male judges in international courts raises questions about the integrity of selection procedures, which can undermine the legitimacy and the public authority of international courts. Grossman persuasively argues this point, and I will thus avoid rehearsing her thoughts here. ${ }^{19}$ A key idea is that women's effective representation is essential to empowering them as valid interlocutors with genuine rights to shape the public space.

\footnotetext{
15 See AnNe-Marie SLAughter, UNFINISHed Business (2015).

${ }^{16}$ Nancy Fraser, From Redistribution to Recognition? Dilemmas of Justice in a Post-Socialist Age, 1 New LeFT Rev. 212 (1995).

17 Anne Phillips, Defending Equality of Outcome, 12 J. POL. PHIL. 1 (2004).

${ }^{18} \underline{I d}$.

${ }^{19}$ See, also, Nienke Grossman, Sex on the Bench: Do Women Judges Matter to the Legitimacy of International Courts?, 12 CHI. J. INT'L L. 647 (2012).
} 


\section{Mindful judging}

Yet at the core of judicial diversity arguments, there is more than equality and democratic legitimacy. They also concern the quality of judging which is seen to be weakened by underrepresentation. This crucial suggestion remains nevertheless contested, as Grossman herself acknowledges, and points to an underexplored issue: What difference does women's presence make to the outcomes of adjudication? After all, judicial adjudication is ideally envisioned as blind, free from prejudice. Despite the great disparity of recruitment systems and institutional designs, judges are ideally portrayed as independent, competent, and impartial officials. While deciding on a particular case, they must follow strict procedural rules, and base their judgments on law, rather than on their personal conceptions of justice. Women's scarce presence should thus not be of particular concern for the outcomes of judicial decision-making.

However, the idealized view of judges as impartial and almost infallible authorities, who can act as a safe haven from majoritarian prejudice, underestimates the concerns about institutional constraints and biases that might impinge on courts' ability to protect vulnerable groups, and might also undermine significantly the required impartiality of adjudicators. After all, the composition of courts (both domestic and international) is made up of middle and upper class professional elites, largely male, as Grossman's research shows.

Surely, it could be objected that such traits do not need to determine, and that they should ideally not even influence, the task of adjudication. But there are solid critiques that challenge this idealized view. The more radically sceptical stance is associated with American realist theorists who regarded judges as ordinary persons with a personal background and an identity, and pointed out that factors such as their education, religion, political views, and cultural belonging can influence their reasoning. Even those who reject the most critical realist accounts against judicial impartiality should acknowledge that the opposing ideal—a Dworkinian Hercules (the immensely wise judge with full knowledge and unlimited time to decide)—remains a metaphor. There is a risk that gender (and cultural, racial, or religious) imbalances affect impartiality, and that judicial decision-making ends up reproducing dominant prejudices and biases.

Let me briefly elaborate on this point. The principle nemo iudex in causa sua — that is, no judge should preside over a matter in which she has a personal interest-is regarded as fundamental in democratic legal systems. Yet it is not only a direct or even conscious personal interest that can be potentially threatening, but also a more unconscious prejudice. This can be manifested more subtly in processes of adjudication led by judges who are typically male and belong to a dominant ethnocultural group. For instance, such judges might simply attend less carefully to the facts of the case, or display a lower level of "perceptual sensitivity" towards the reasoning or arguments invoked by minority claimants. ${ }^{20}$ Although I cannot provide a proper normative account of this dimension of judging here, ${ }^{21}$ the idea is well captured by Amalia Amaya's argument that the practical reasoning of a virtuous (decision-making) agent is not merely dependent on applying a set of general principles or rules, but on showing the capacity to recognize the salient features of a given situation. ${ }^{22}$

Empathy, indeed, might play a crucial role in conflicts involving women or minority litigants. Yet, as Maks Del Mar stresses, empathy is not just an affective state, but has an important cognitive dimension. ${ }^{23}$ This dimension can be significantly abridged if the adjudicator is not critically aware of the likely presence of biases or prejudices, or if she is insufficiently attentive or alert to the social contempt against certain identities. The problem, in brief, is one of adjudicators being less mindful, and hence less objective and impartial, in

20 See Maksymilian Del Mar, Judging Virtuously: Developing an Emphatic Capacity for Perceptual Sensitivity, 5 JuRIS. 177 (2014).

${ }^{21}$ I develop this argument in: Neus Torbisco-Casals, Multiculturalism, Identity Claims and Human Rights: From Politics to Courts, Law \& EтHics Hum. RTS. (forthcoming).

22 Amalia Amaya, The role of virtue in legal justification, in LAW, ViRTUE AND JustiCE (Amalia Amaya \& Ho Hock Lai eds. 2013).

23 See Del Mar, supra note 21. 
assessing the claims of members in vulnerable groups, as their capacity to be responsive to their "otherness," and to assess their reasons fairly, might simply be impaired by their position as members of the dominant culture. As a result, judgments might replicate, and contribute to solidifying, existing social prejudices. ${ }^{24}$

The risk of unmindful judging thus arises when judges cannot attach enough significance to the experiences and perspectives of members in socially subordinated groups, such as women. Hence, increasing the presence of women on court benches is not aimed at reifying difference, but rather at improving the integrity of judging, transforming legal interpretations that remain biased against their identities. This is the underlying point in Fareda Banda's discussion on crimes of rape and other sexual offences. ${ }^{25}$ The same idea has been recently expressed by prominent legal voices who have strongly criticized the light sentence handed to a former Stanford University elite swimmer convicted for sexual assault. ${ }^{26}$ Stanford Law Professor Michele Dauber couldn't be more explicit in claiming that "we need more women judges who understand that rape is not a mistake." 27

\section{Trust}

As defenders of judicial review typically assert, courts can play a key role in incorporating the viewpoints of vulnerable minorities and powerless groups, thereby facilitating their protection and inclusion as genuine members of the community. The international judiciary should not be an exception in this regard. When rulings reflect an effort to hear the voices of women, or of marginalized minorities, and to treat their reasons fairly, they have a potential for helping to overcome dominant prejudices against these groups as well as stereotypes of their members. Eventually, this might help to generate a virtuous cycle of intergroup trust and understanding, which makes it possible to speak of a genuine "community of equals." 28 Instead, to the extent that women, or minority litigants, perceive the judicial processes (or the outcomes) as biased against their identities, this might be detrimental to tackling pervasive distrust.

\section{Conclusion}

Grossman's article exposes women's persisting underrepresentation in international courts and calls for substantial reforms to tackle the challenge of inclusion. In line with her own remarks, I have argued that the current situation is not just dysfunctional, but unfair, as it reveals a systemic pattern of sex inequality that needs to be corrected. Predominant legal interpretations of equality can hardly engage systemic forms of group disadvantage. Failure to develop mechanisms to correct gender imbalances might thus not be attributed to an oversight, but rather to the continuing force of a faulty conception of equality that should be revised. Tackling current sex imbalances in international court benches can be critical not just to achieve real equality between men and women, but also to further the integrity of judging as well as fundamental social and democratic values.

\footnotetext{
${ }^{24}$ Institutional theories of judicial behavior, which accentuate the relevance of "systemic," rather than personal or apparent bias, are crucial here. Apparent bias occurs where there is sufficient evidence of personal interest of a certain judge; systemic bias, instead, focuses on whether an adjudication system is designed to systematically favor the appointment of members of mainstream social groups, which typically reproduce their shared values and prejudices.

${ }^{25}$ Fareda Banda, "If you buy a cup, why would you not use it?" Marital Rape: The Acceptable Face of Gender Based Violence, 109 AJIL UNBOUND 321 (2016).

${ }^{26}$ See on this case Marina Koren, Telling the Story of the Stanford Rape Case, THE ATLANTIC (June 6, 2016).

27 See Veronica Rocha \& Richard Winton, Stanford rape sentence unusually light, legal experts say, L.A. Times (June 7, 2016, 12:12 PM).

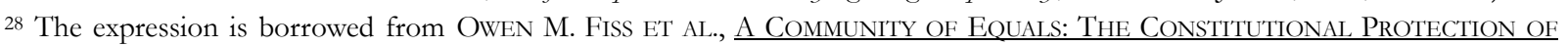
NEW AMERICANS (1999).
} 